\title{
Protective efficiency of Chelidonium majus extract against hepatoimmune and DNA changes induced by aflatoxin B1
}

\author{
Heba F. Gomaa ${ }^{1,2}$, Nevein N. Fadl ${ }^{3}$, Wael MA Elmashad ${ }^{4}$, Dalia M. Abouelfadl ${ }^{5}$, Fathia A. Mannaa ${ }^{3}$, Khaled G. Abdel-Wahhab ${ }^{3 *}$ \\ ${ }^{1}$ Biology Department, College of Sciences and Arts, Scientific Department, Qassim University, Burydah, Saudi Arabia. \\ ${ }^{2}$ Zoology Department, Faculty of Science, Ain Shams University, Cairo, Egypt. \\ ${ }^{3}$ Medical Physiology Department, National Research Centre, Dokki, Egypt. \\ ${ }^{4}$ Physiology Department, Faculty of Medicine, Tanta University, Tanta, Egypt. \\ ${ }^{5}$ Pathology Department, National Research Centre, Dokki, Egypt.
}

\begin{tabular}{l}
\hline ARTICLE INFO \\
\hline Received on: 26/06/2021 \\
Accepted on: 12/11/2021 \\
Available Online: 05/03/2022 \\
\\
\hline Key words: \\
Aflatoxin B1, Chelidonium \\
majus, oxidative stress, liver, \\
antioxidant.
\end{tabular}

antioxidant.

\begin{abstract}
Aflatoxin B1 (AFB1) has potent hepatotoxic and carcinogenic effects. The objective of the present study was to evaluate the protective effect of the Chelidonium ethanolic extract (CEE) against the AFB1-induced hepatotoxicity in rats. Thirty-two male albino rats (5 months old) were grouped and treated intragastrically for 28 days as follows: 1) control: each rat was given $1.0 \mathrm{ml}$ vehicle daily [Dimethyl sulfoxide -phosphate saline (DMSO-PBS) buffer containing $44 \mathrm{mg}$ DMSO]; 2) animals received the CEE (300 mg/kg/day); 3) animals received AFB1 (80 $\mu \mathrm{g} / \mathrm{kg} / \mathrm{day})$, and 4) animals received both AFB1 $(80 \mu \mathrm{g} / \mathrm{kg} /$ day $)$ and the CEE $(300 \mathrm{mg} / \mathrm{kg} /$ day $)$. The results declared that AFB1 intoxication induced significant increases in alanine aminotransferase, aspartate aminotransferase, gamma-glutamyl transferase, alkaline phosphatase, triglycerides, total cholesterol, low density lipoprotein (LDL)- cholesterol, creatinine, urea, inflammatory cytokines (interleukin-1beta and tumor necrosis factor-alpha), tumor markers (alpha-fetoprotein and carcinoembryonic antigen), DNA fragmentation, nitric oxide, and malondialdehyde coupled with a significant reduction in high density lipoprotein (LDL)- cholesterol, glutathione peroxidase, superoxide dismutase, catalase, and glutathione values, while the group that received the $\mathrm{CEE}$ alone showed insignificant changes in these parameters as compared with the control one. Interestingly, coadministration of the CEE besides AFB1 significantly prevented the above mentioned deteriorations; moreover, the histopathological examination of the liver in group four revealed a better ameliorative pattern by CEE treatment. In conclusion, the CEE exhibits a pronounced antioxidative activity, making it promising as a protective and immunomodulatory agent against aflatoxins' health risks.
\end{abstract}

\section{INTRODUCTION}

Aflatoxin B1 (AFB1), a mycotoxin, is a secondary metabolite that is mostly produced by the Aspergillus parasiticus and Aspergillus flavus fungi (Ismail et al., 2018). AFB1 is present in foods, grains, and feedstuffs as a natural contaminant (Alm-Eldeen et al., 2015). It exerts deleterious effects on both humans and animals (Ishikawa et al., 2017). Ingestion of AFB1contaminated products can cause immunosuppressive (Zhang

\footnotetext{
*Corresponding Author Khaled G. Abdel-Wahhab, Medical Physiology Department, National Research Centre,Dokki,Egypt.E-mail:kgm194@yahoo.com
}

et al., 2019) and teratogenic and mutagenic disturbances (Diao et al., 2013). It is a strong carcinogenic agent due to its potential in inducing oxidative stress and disturbance in the antioxidant defense mechanisms (Alm-Eldeen et al., 2015), so it was classified among the first group of carcinogens (Eaton et al., 1994).

Also, AFB1 is potently hepatotoxic as its ingestion causes hepatocellular hyperplasia, cirrhosis, hepatic necrosis, and acute liver damage in both humans and animals (Murphy et al., 2006). AFB1 is metabolized by cytochrome P450 in the liver, resulting in the extreme production of free radicals such as hydrogen peroxide and superoxide ion leading to oxidative exertion that could be neutralized by the antioxidants (Mohajeri et al., 2018). Many investigators have confirmed the beneficial role 
of antioxidant agents as a granulated strategy for liver protection from the toxicity of aflatoxins (El-Bahr, 2015).

The Chelidonium majus L (C. majus) plant is a member of the Papaveraceae family and is known as greater celandine (Gilca et al., 2010). The extracts of C. majus have been shown to exhibit antispasmodic (Hiller et al., 1998) and anti-inflammatory (Jang et al., 2004) activities. It showed also antitumor and antigenotoxic effects (Biswas et al., 2002). In addition, it is used in the treatment of liver disorders (Vahlensieck et al., 1995) and gallbladder and digestive dysfunctions (Barnes et al., 2007). Furthermore, the alkaloids of $C$. majus exhibit an analgesic action as in morphine (Hiller et al., 1998). The medicinal attention to C. majus is due to its pharmaceutical components, such as phenolic compounds, flavonoids, alkaloids, and proteins (Nawrot et al., 2014). Ukrain, an alkaloid, which is derived from C. majus, was found to have antineoplastic, antitumor, and immunomodulatory properties (Bozeman et al., 2012). This study was conducted to determine (in vitro) the phenolic constituents, radical scavenging activity (RSA), and reducing power potential of the C. majus ethanolic extract for exploring (in vivo) its antioxidant and protective efficiencies against oxidative stress and hepatotoxicity in AFB1intoxicated rats.

\section{MATERIALS AND METHODS}

\section{Chemicals}

AFB1 was purchased from the Cayman Chemical Co. (USA). DMSO was obtained from Heiltropfen Co. (Germany). All other chemicals were of the highest analytical grade and were obtained from national research center stores.

\section{Extraction}

The aerial parts of C. majus were obtained from Abd El-Rahman Harraz (Bab El-Khalk Zone, Cairo, Egypt). The plant was authenticated in the Botany Department, Faculty of Science, Cairo University. The plant carries the taxonomic serial number 501481. The plant was ground and mixed with $70 \%$ ethyl alcohol $(1: 5 \mathrm{w} / \mathrm{v})$, and the mixture was kept at room temperature for 48 hours in a closed container and then filtered, and the ethanol was evaporated from the filtrate using a rotary evaporator and freezedried to remove water residues (Filipiak-Szok et al., 2017). The resulting extract yield $(\%)$ was calculated and stored at $-20^{\circ} \mathrm{C}$ until further use.

\section{In vitro assessments of the extract}

The assessment of the RSA of the CEE by the 2,2-diphenyl-1-picrylhydrazyl (DPPH) assay was carried out using the Nogala-Kalucka et al. (2005) method. The RSA was calculated as the percentage of the scavenged DPPH for three replicates.

The estimation of the ferric-reducing power of the CEE was carried out using the modified method described by Sethiya et al. (2014). The reducing power of the CEE was calculated as ascorbic acid equivalent from the standard curve of ascorbic acid.

\section{In vivo study and experimental design}

Five-month-old male albino rats (150-170 g) were purchased from the Animal Colony, Research Institute of
Ophthalmology, Egypt. One week before the experiment, the animals were maintained in plastic cages for acclimatization. All animals were treated ethically according to the Ethical Committee of the National Research Centre (FWA 00014747) that in turn approved the protocol of this study. After adaptation, the rats were divided randomly into four groups (eight rats each) and were orally treated by a gastric tube as follows: each animal in group one was daily given $1.0 \mathrm{ml}$ DMSO-PBS buffer ( $\mathrm{pH} 7.2$ ) containing $44 \mathrm{mg}$ DMSO and this served as the control group, the animals in group two were given the CEE (300 mg/kg/day) (Zarei et al., 2015) dissolved in the DMSO-PBS buffer, the animals in group three were administered with AFB1 $(80 \mu \mathrm{g} / \mathrm{kg} /$ day) (Abdel-Wahhab et al., 2015) dissolved in the DMSO-PBS buffer, and the animals in group 4 were given AFB1 $(80 \mu \mathrm{g} / \mathrm{kg} /$ day) in combination with the CEE (300 mg/ $\mathrm{kg} /$ day). All groups were treated for 28 days.

\section{Blood and tissue sampling}

After 28 days, fasting blood samples were collected from the retro-orbital plexus of rats (Schermer, 1967) into polyethylene tubes and cool-centrifuged. The serum was separated, divided into aliquots, and stored at $-80^{\circ} \mathrm{C}$ till analysis. After the blood collection, the animals were killed by sudden decapitation; then, the liver was removed, washed in saline, and dried on filter paper. A certain weight from each liver was homogenized in phosphate buffer ( $\mathrm{pH} 7.4$ ) to give $10 \% \mathrm{w} / \mathrm{v}$ homogenate. Then, the homogenate was centrifuged at $1,700 \mathrm{rpm}$ at $4^{\circ} \mathrm{C}$ for 10 minutes (Lin et al., 1998), and the supernatant was stored at $-70^{\circ} \mathrm{C}$ until the analysis of oxidative stress markers. One part from each liver was rolled in aluminum foil and stored at $-80^{\circ} \mathrm{C}$ for the determination of DNA fragmentation level. Another part of the liver was immersed in a formaldehyde-saline $(10 \% \mathrm{v} / \mathrm{v})$ solution for histopathological examination.

\section{Serum biochemical measurements}

The activity of serum alanine aminotransferase (ALT), aspartate aminotransferase (AST), alkaline phosphatase (ALP), and gamma-glutamyl transferase (GGT) was assessed spectrophotometrically using reagent kits purchased from CliniSciences, France. The concentration of creatinine and urea was measured in the serum using reagent kits purchased from BioVision, Inc., USA. The levels of triglycerides, total cholesterol, LDL-cholesterol (LDL-C), and HDL-cholesterol (HDL-C) were tested using reagent kits obtained from Cell Biolabs, USA. The determination of serum carcinoembryonic antigen (CEA), alpha-fetoprotein (AFP), tumor necrosis factoralpha (TNF- $\alpha$ ), and interleukin-1beta (IL-1 $\beta$ ) was carried out using rats' reagent ELISA kits purchased from Sinogeneclon Biotech Co., Hangzhou, China.

\section{Estimation of oxidative stress markers}

Hepatic lipid peroxidation (measured as malondialdehyde, MDA), nitric oxide (NO), and reduced glutathione (GSH) levels and also the enzymatic activity of glutathione peroxidase (GPx), superoxide dismutase (SOD), and catalase (CAT) were determined spectrophotometrically using kits purchased from Biodiagnostic Co., Giza, Egypt. 

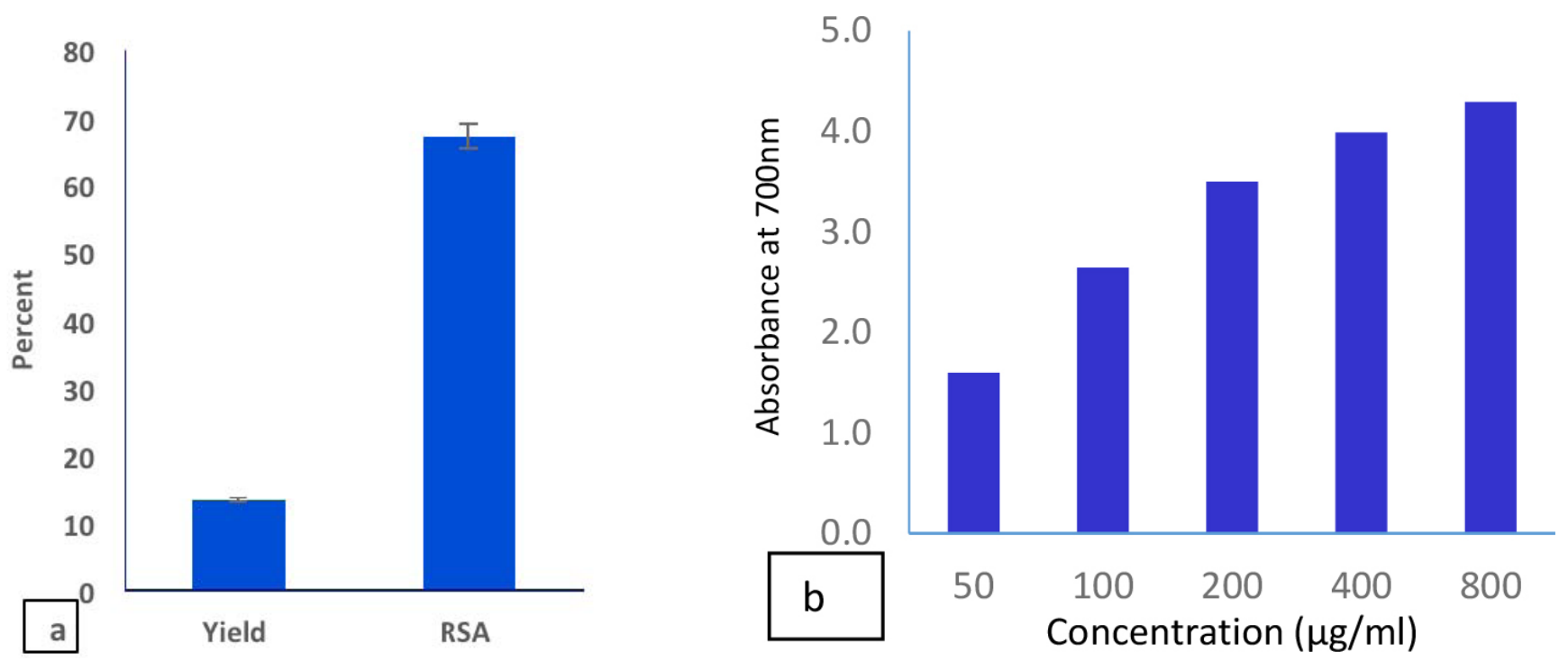

Figure 1. Yield and RSA (a); reducing power (b) of the C. majus ethanolic extract.

Table 1. HPLC analysis of phenolic ingredients of the $C$. majus ethanolic extract.

\begin{tabular}{cccc}
\hline & Area & $\begin{array}{c}\text { Conc. } \\
(\boldsymbol{\mu g} / \mathbf{m l}=\boldsymbol{\mu g} / \mathbf{2 5 . 5} \mathbf{~ m g})\end{array}$ & Conc. $(\boldsymbol{\mu g} / \mathbf{g})$ \\
\hline Gallic acid & 940.88 & 91.45 & $3,586.09$ \\
Chlorogenic acid & $1,151.19$ & 93.75 & $3,676.49$ \\
Methyl gallate & 16.16 & 0.23 & 8.99 \\
Caffeic acid & 661.30 & 22.76 & 892.47 \\
Syringic acid & 694.45 & 29.13 & $1,142.33$ \\
Ellagic acid & 120.72 & 11.90 & 466.85 \\
Coumaric acid & 45.09 & 0.76 & 29.66 \\
Vanillin & 565.17 & 12.25 & 480.27 \\
Ferulic acid & 848.59 & 27.88 & $1,093.26$ \\
Naringenin & 247.07 & 13.63 & 534.43 \\
Taxifolin & 208.53 & 18.06 & 708.14 \\
Cinnamic acid & 863.66 & 8.16 & 319.89 \\
Kaempferol & 217.91 & 11.77 & 461.44 \\
\hline
\end{tabular}

\section{Determination of DNA fragmentation}

The quantitative determination of the percentage of the fragmented DNA was carried out using the method of Perandones et al. (1993).

\section{Histopathological examination}

Liver sections of $5 \mu \mathrm{m}$ thickness were processed and stained for histological examination under light microscopy (Drury and Wallington, 1980).

\section{Statistical analysis}

The obtained data were subjected to the one-way analysis of variance followed by Duncan's multiple post hoc test at a significance level of $p \geq 0.05$. This was carried out using the Statistical Analysis System (SAS, 1998) program software [copyright (c) by SAS Institute Inc. (Cary, NC)].

\section{Results}

The in vitro study indicated the antioxidant properties of the C. majus ethanolic extract (CEE), which appeared from testing the RSA and reducing power of the extract (Fig. 1). The extract scavenged $67 \%$ of the DPPH free radical. We noticed also that the reducing power increases with increasing the concentration of the extract. The phytochemical analysis of the CEE using HPLC revealed the identification of 13 phenolic compounds. Among these, gallic acid, chlorogenic acid, syringic acid, and ferulic acid were the major phenolic components in the extract (Table 1 and Fig. 2). The intoxication with AFB1 resulted in serious degeneration in the rats' livers, where a significant elevation was observed in serum ALT, AST, ALP, and GGT activities; also, urea and creatinine levels increased significantly, while these parameters showed nonremarkable changes in the rats' group that received the CEE alone relative to the control group, indicating the safety of the CEE, at the used dose, on hepatic 


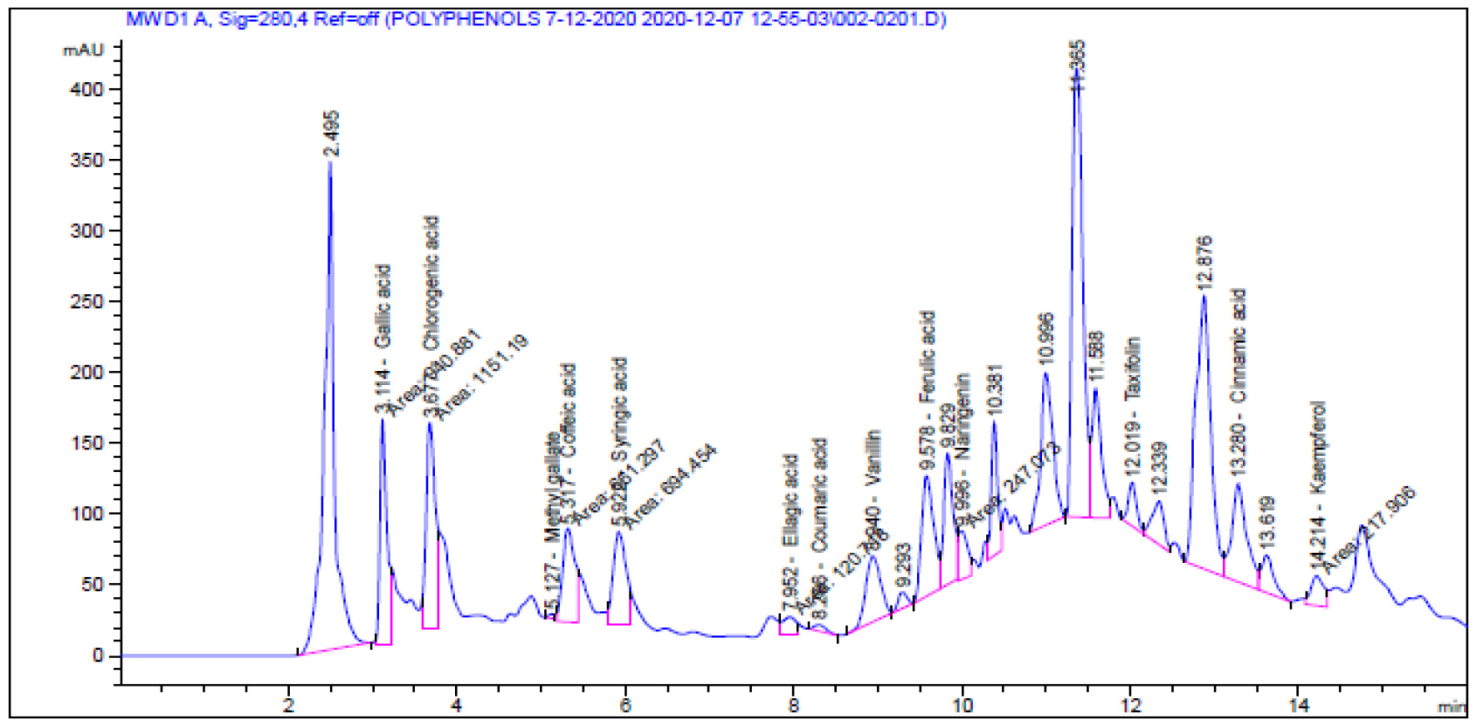

Figure 2. HPLC imprint profile of the C. majus ethanolic extract.

Table 2. Serum biochemical measurements of CEE- and AFB1-treated rats.

\begin{tabular}{ccccc}
\hline Parameter & Control & CEE & AFB1 & AFB1 + CEE \\
\hline ALT (IU/l) & $32 \pm 0.3 .6$ & $31 \pm 2.7$ & $184 \pm 8.3^{\mathrm{a}}$ & $85.3 \pm 6.56^{\mathrm{b}}$ \\
AST (IU/l) & $32 \pm 0.3 .6$ & $28 \pm 3.1$ & $121 \pm 5.5^{\mathrm{a}}$ & $78.6 \pm 9.6^{\mathrm{b}}$ \\
ALP (IU/l) & $84 \pm 4.38$ & $83 \pm 7.4$ & $256.4 \pm 11.4^{\mathrm{a}}$ & $375.4 \pm 12.5^{\mathrm{b}}$ \\
GGT (IU/l) & $53 \pm 2.8$ & $49 \pm 2.4$ & $152 \pm 8.9^{\mathrm{a}}$ & $142.1 \pm 3.8^{\mathrm{b}}$ \\
Urea (mg/dl) & $32 \pm 1.97$ & $29 \pm 2.1$ & $41 \pm 3.1^{\mathrm{a}}$ & $35.1 \pm 4.9^{\mathrm{b}}$ \\
Creatinine (mg/dl) & $0.73 \pm 0.17$ & $0.71 \pm 0.07$ & $0.93 \pm 0.21^{\mathrm{a}}$ & $0.85 \pm 0.12^{\mathrm{b}}$ \\
Total-C (mg/dl) & $81.7 \pm 4.1$ & $78.3 \pm 3.9$ & $187.2 \pm 5.9^{\mathrm{a}}$ & $107.6 \pm 5.1^{\mathrm{b}}$ \\
Triglyceride (mg/dl) & $75.8 \pm 3.3$ & $74.8 \pm 4.1$ & $191.5 \pm 6.3^{\mathrm{a}}$ & $92.3 \pm 4.1^{\mathrm{b}}$ \\
LDL-C (mg/dl) & $27.2 \pm 1.7$ & $26.5 \pm 1.9$ & $56.7 \pm 2.8^{\mathrm{a}}$ & $33.4 \pm 4.4^{\mathrm{b}}$ \\
HDL-C (mg/dl) & $46.3 \pm 2.6$ & $45.8 \pm 2.7$ & $31.3 \pm 2.2^{\mathrm{a}}$ & $40.5 \pm 2.9^{\mathrm{b}}$ \\
\hline
\end{tabular}

Values are mean $\pm \mathrm{SE}$ for eight rats.

AFB1: aflatoxin B1; CEE physiological markers,: Chelidonium majus ethanolic extract.

${ }^{a}$ Compared with the control group while ${ }^{\mathrm{b}}$ compared with the AFB1 group at $p \leq 0.05$.

and renal functions. Favorably, treatment of rats with the CEE together with AFB1 produced a significant improvement in the above mentioned physiological markers, as the extract succeeded in restoring the elevated values close to those of the control group (Table 2).

Table 2 also shows the serum lipid profiles in the different studied groups. In comparison with the control group, the obtained data indicated that AFB1 ingestion significantly increased the concentrations of triglycerides, total cholesterol, and LDL-C, whereas it significantly decreased the concentration of HDL-C, whereas the ingestion of the CEE alone did not change the levels of lipid profile parameters. Interestingly, animals treated with the CEE in line with AFB1 showed a significant increase in HDL-C level associated with a significant decrease in the levels of triglycerides, total cholesterol, and LDL-C as compared to the AFB1-treated group.

Table 3 depicts the results of serum tumor and inflammatory markers in the different studied groups. AFB1 ingestion produced a significant increase in serum tumor markers (AFP and CEA) and inflammatory cytokines (IL-1 $\beta$ and TNF- $\alpha$ ). The CEE never deteriorated these parameters when it was administrated separately; favorably, it markedly succeeded in downregulating the elevation of the measured tumor and inflammatory markers that resulted from AFB1 intoxication.

With respect to the redox status of the hepatic tissue, AFB1 intoxication displayed significant increases in $\mathrm{NO}$ and MDA, concomitant with a significant drop in GPx, SOD, and CAT activities as well as GSH level compared to the control group, while these values of oxidative stress markers did not negatively change in animals that received the CEE alone. Coadministration of the CEE with AFB1 showed a considerable protecting action against the oxidative stress deterioration induced by AFB1 intoxication (Table 4).

Concerning the effect of AFB1 on DNA (Fig. 3), animals intoxicated with AFB1 showed a significant rise in the ratio of fragmented DNA compared to the control rats. Cotreatment of rats with the CEE in line with AFB1 induced a moderate protective 
Table 3. Serum tumor and immunoinflammatory markers of CEE- and AFB1-treated rats.

\begin{tabular}{ccccc}
\hline Parameter & Control & CEE & AFB1 & AFB1+CEE \\
\hline CEA $(\mathrm{ng} / \mathrm{ml})$ & $1.66 \pm 0.06$ & $1.64 \pm 0.16$ & $7.57 \pm 0.72^{\mathrm{a}}$ & $3.13 \pm 0.08^{\mathrm{b}}$ \\
AFP $(\mathrm{ng} / \mathrm{ml})$ & $0.62 \pm 0.19$ & $0.67 \pm 0.07$ & $2.81 \pm 0.11^{\mathrm{a}}$ & $1.69 \pm 0.44^{\mathrm{b}}$ \\
IL-1 $\beta(\mathrm{ng} / \mathrm{ml})$ & $7.6 \pm 1.65$ & $7.8 \pm 1.44$ & $30.2 \pm 2.41^{\mathrm{a}}$ & $18.6 \pm 1.89^{\mathrm{b}}$ \\
TNF- $\alpha(\mu \mathrm{g} / \mathrm{ml})$ & $10.4 \pm 0.24$ & $11.08 \pm 0.94$ & $41.9 \pm 5.32^{\mathrm{a}}$ & $27.5 \pm 0.65^{\mathrm{b}}$ \\
\hline
\end{tabular}

Values are mean \pm SE for eight rats.

AFB1: aflatoxin B1; CEE: Chelidonium majus ethanolic extract.

${ }^{a}$ Compared with the control group while ${ }^{\mathrm{b}}$ compared with the AFB1 group at $p \leq 0.05$.

Table 4. Hepatic oxidative stress markers of CEE- and AFB1-treated rats

\begin{tabular}{ccccc}
\hline Parameter & Control & CEE & AFB1 & AFB1+CEE \\
\hline MDA (nmol/g tissue) & $154 \pm 8.1$ & $152 \pm 7.7$ & $354 \pm 12.4^{\mathrm{a}}$ & $208 \pm 9.9^{\mathrm{b}}$ \\
NO ( $\mu$ mo1/g tissue) & $60 \pm 4.2$ & $59 \pm 5.8$ & $183 \pm 8.7^{\mathrm{a}}$ & $84 \pm 6.6^{\mathrm{b}}$ \\
GSH (mmo1/g tissue) & $5.11 \pm 0.44$ & $5.21 \pm 0.46$ & $2.11 \pm 0.32^{\mathrm{a}}$ & $4.3 \pm 0.47^{\mathrm{b}}$ \\
GPx (U/g tissue) & $5,930 \pm 106$ & $5,870 \pm 117$ & $2,174 \pm 94^{\mathrm{a}}$ & $4,142 \pm 109^{\mathrm{b}}$ \\
SOD (U/g tissue) & $9,684 \pm 151$ & $9,768 \pm 125$ & $4,572 \pm 127^{\mathrm{a}}$ & $8,022 \pm 105^{\mathrm{b}}$ \\
CAT (U/g tissue) & $91 \pm 2.9$ & $93 \pm 4.2$ & $47 \pm 3.9^{\mathrm{a}}$ & $77 \pm 6.6^{\mathrm{b}}$ \\
\hline
\end{tabular}

Values are mean \pm SE for eight rats.

AFB1: aflatoxin B1; CEE: Chelidonium majus ethanolic extract.

${ }^{a}$ Compared with the control group while ${ }^{\mathrm{b}}$ compared with the AFB1 group at $p \leq 0.05$.

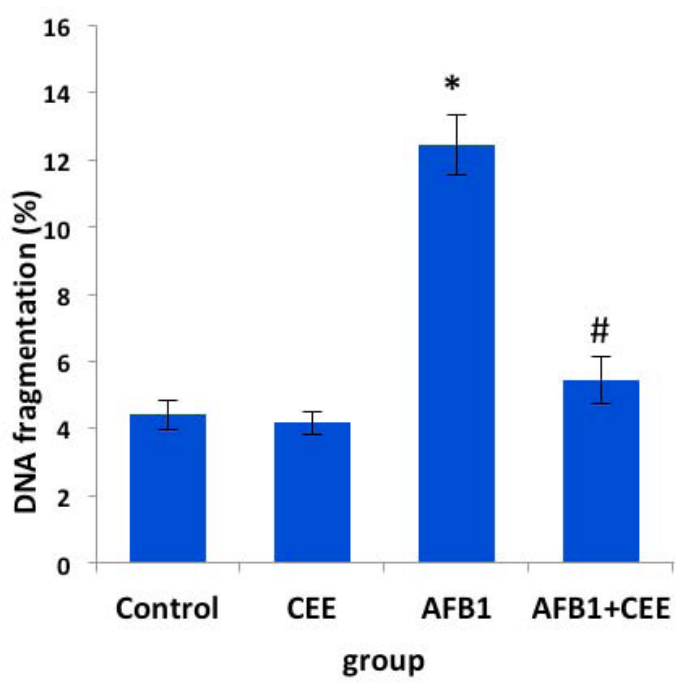

Figure 3. Effect of oral ingestion of the CEE on hepatic DNA fragmentation. Values are mean \pm SE for eight rats. *Compared with the control group while ${ }^{\#}$ compared with the AFB1 group at $p \leq 0.05$. AFB1: aflatoxin $\mathrm{B} 1$; CEE: C. majus ethanolic extract.

effect against the AFB1-induced DNA damage; this was achieved from the significant drop in the fragmented DNA amount.

The hepatic histopathological findings of the control group, as well as the CEE-treated one, revealed normal hepatocytes architecture (Fig. 4A and B). In contrast, the liver sections of the
AFB1-intoxicated rats showed damaged livers with the dense portal and lobular inflammation associated with fibrosis (Fig. 5), while sections obtained from rats that received the CEE besides AFB1 showed liver tissues having preserved architecture and negligible sight of inflammation (Fig. 6). 


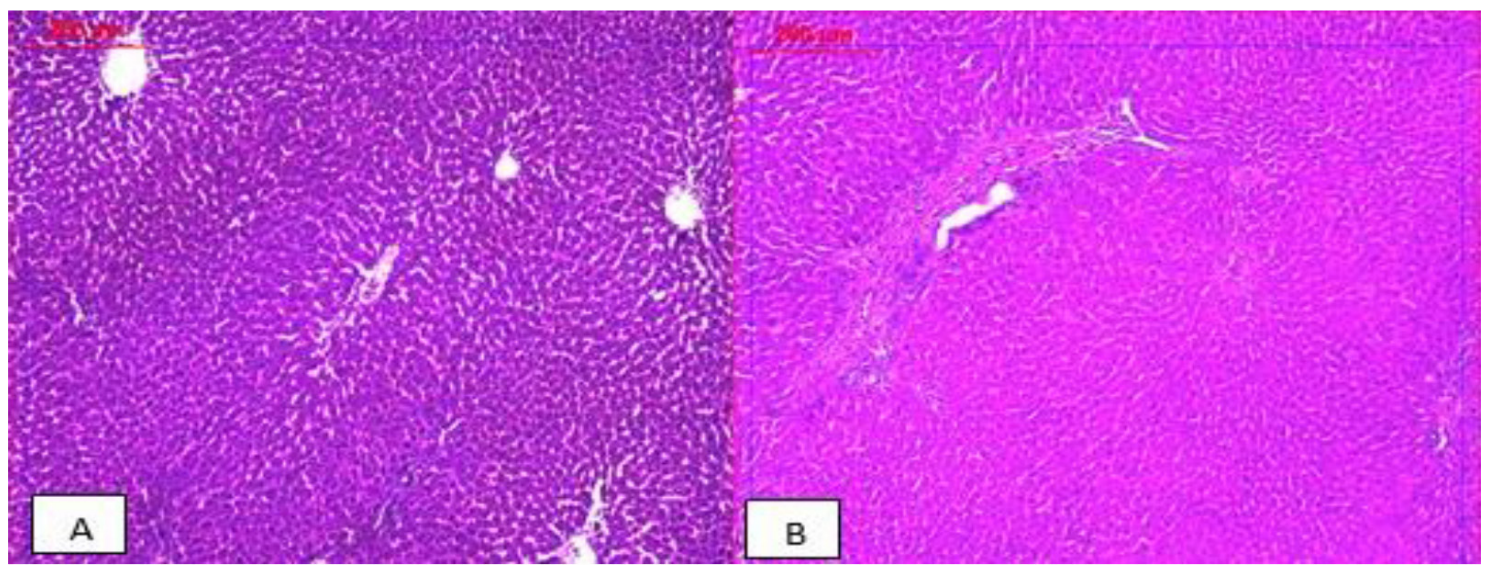

Figure 4. Photomicrographs of the livers' sections of healthy control rats (A) and rats orally administrated with the C. majus ethanolic extract (B). Both sections show preserved architecture with normal hepatocytes and central vein $(\times 100)$.

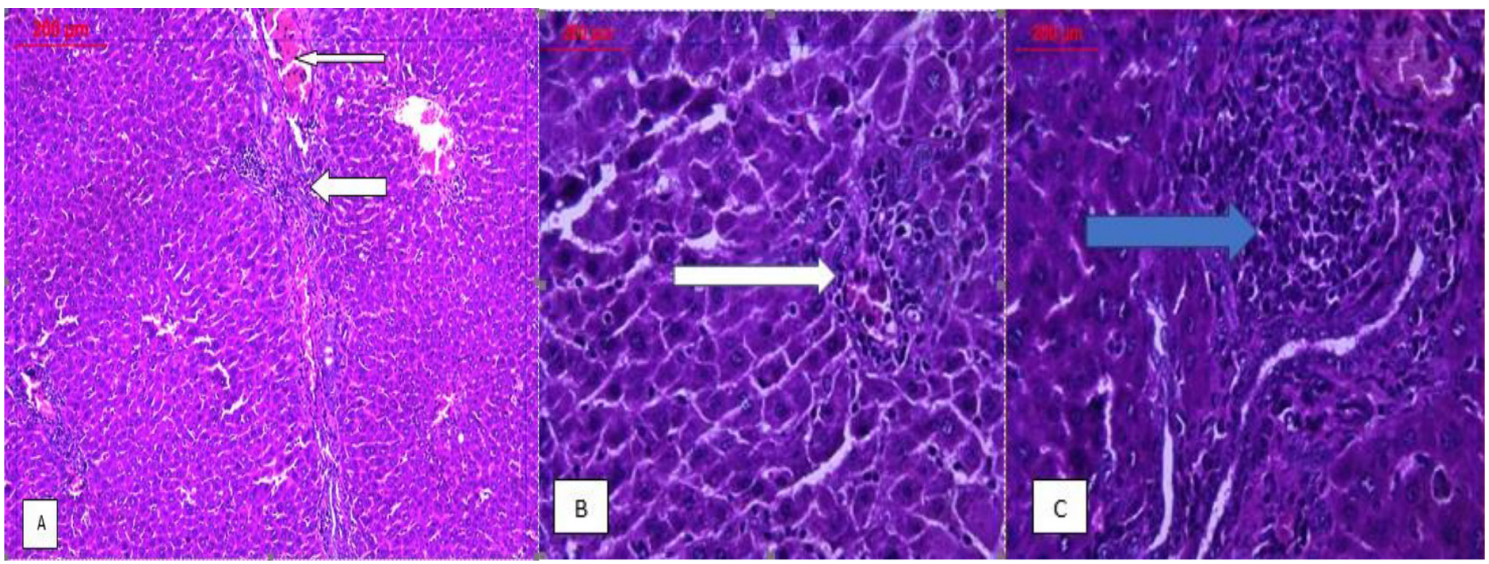

Figure 5. Photomicrographs of livers' sections of rats intoxicated with AFB1; (A) low power $(\times 100)$ view demonstrating the portal inflammation (thick arrow), central vein congestion and portal fibrosis (thin arrow), (B) high power $(\times 400)$ view showing damaged liver with lobular inflammation (white arrow), and (C) another high power $(\times 400)$ view illustrating the dense portal inflammation associated with fibrosis (blue arrow).

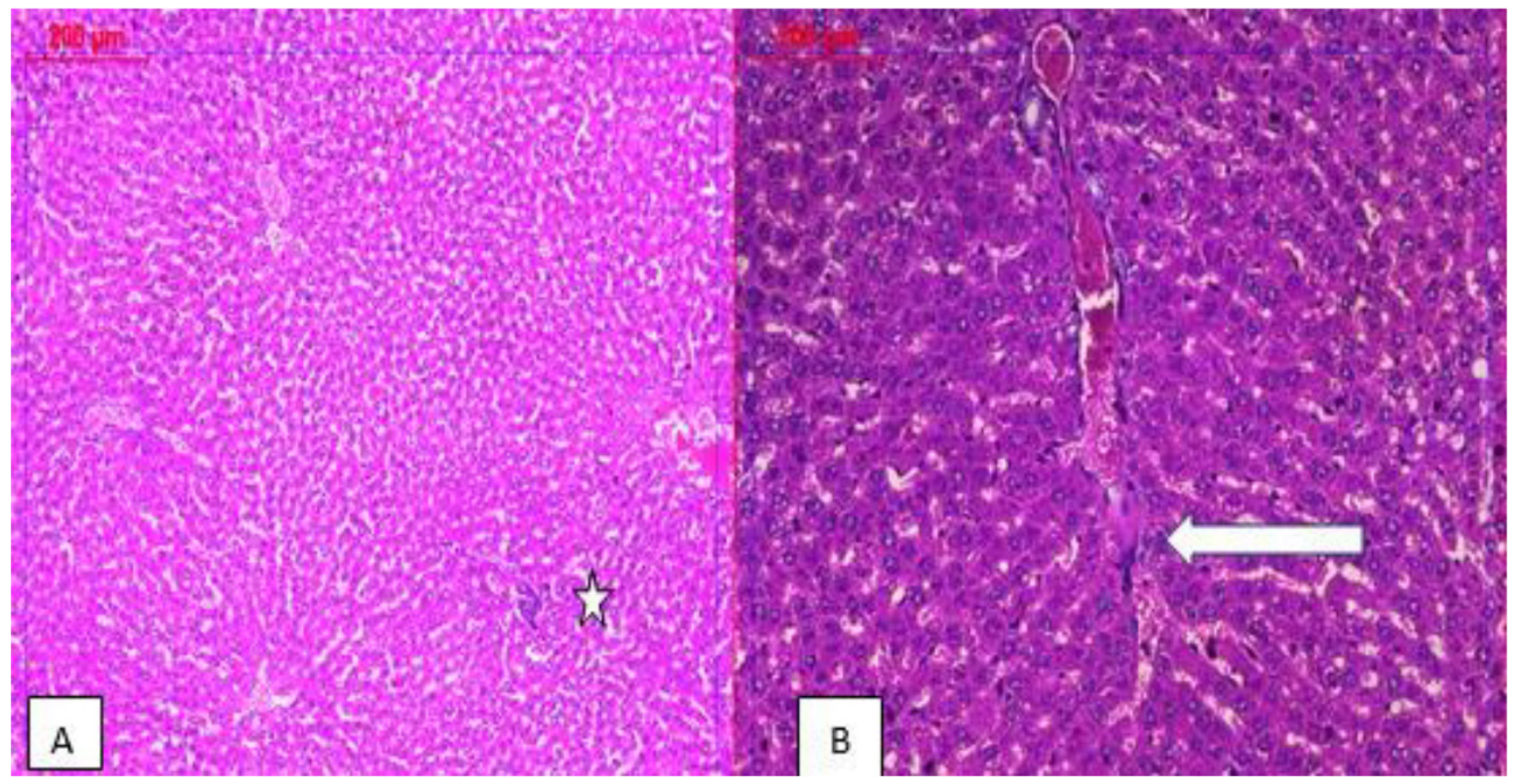

Figure 6. Photomicrographs of livers' sections of rats that received the C. majus ethanolic extract in combination with AFB1; low power $(\times 100)$ view showing liver tissue with preserved architecture and negligible inflammation within normal limits (white star) (A); medium power $(\times 200)$ view illustrating that mild vascular congestion was also noted (B). 


\section{DISCUSSION}

The liver is the major site of xenobiotic metabolism (Wang et al., 2007). It is considered one of the important body organs, where it detoxifies or eliminates toxins and foreign substances (Khan, 2006). In the present study, AFB1 intoxication induced liver dysfunction that appeared from the significant elevation in the activities of the serum enzymes ALT, AST, ALP, and GGT compared to the control group. These enzymes are liberated into the bloodstream after cellular damage, so the leakage of these enzymes into the blood may be related to the injury in the hepatic cell membrane (Recknagel et al., 1991). These results are in agreement with the findings of Eftekhari et al. (2018) and Monmeesil et al. (2019). Moreover, the increases in urea and creatinine levels in the AFB1-treated group demonstrated the deleterious and stressful effect on kidney tissue; this result is in line with those obtained by Hamzawy et al. (2013).

AFB1 toxicity mainly targets the liver because AFB1 is metabolized largely in the liver, by the cytochrome P450 enzyme system, to form reactive 8,9-epoxide (Choy, 1993; McLean and Dutton, 1995; Sergent et al., 2008), and it is also metabolized to some extent in extrahepatic tissues (Sergent et al., 2008). AFB1 toxicity is mainly attributed to the binding of the epoxide to DNA to form DNA adducts. The induction of high levels of DNA adducts leads to cellular injury (Ellis, 2009; McLean and Dutton, 1995) and causes hepatic damage such as hemorrhage, cellular necrosis, injury of intrahepatic bile ducts, and elevation in liver enzymes (Rawal et al., 2010).

Treatment of AFB1-intoxicated rats with the CEE significantly reduced the markers of liver and kidney functions. This indicated the hepato- and renoprotective potential of the $\mathrm{CEE}$, which may be due to the presence of phytochemicals. Previously, it has been shown that treatment with the $C$. majus extract could reduce the increased values of transaminases and bilirubin induced by carbon tetrachloride exposure (Mitra et al., 1992 and 1996).

We observed in our study significant increases in the concentrations of triglycerides, total cholesterol, and LDL-C concomitant with a significant decrease in HDL-C level in rats given AFB1 alone, while treatment with the CEE besides AFB1 reversed these values and returned these levels towards those of the control values. The marked increases in triglycerides, cholesterol, and HDL-C reported in the AFB1intoxicated group and the significant reduction in HDL-C level agree with those reported previously by Abdel-Wahhab et al. (2007 and 2010). The increments in serum levels of cholesterol and triglycerides are correlated with hepatic dysfunction and biliary obstruction (Edrington et al., 1995). Also, Marcus and Milton (1982) reported that cholesterol concentration is linked with metabolic functions, which are affected by the liver and kidney integrity.

In the current study, AFB1 significantly increased CEA and AFP levels, and treatment with the CEE besides AFB1 reduced these levels. CEA and AFP are specific markers for liver cancer. AFB1 enhances the formation of reactive oxygen species that cause DNA damaging, which leads to carcinogenesis (Yang et al.,
2000). On the other hand, AFB1 induced hepatocarcinogenesis and DNA damage by promoting apoptosis through the increment in caspase-3, Bax, and p53 expression and the decrement in Bcl2 expression (Liao et al., 2014). The elevation in AFP and CEA levels is in accordance with a previous study which indicated that AFB1 ingestion could increase AFP and CEA levels in rats (Abdel-Wahhab et al., 2010).

The participation of inflammatory mediators in mycotoxin toxicity has been reported (Akinrinmade et al., 2016). IL- $1 \beta$ and TNF- $\alpha$ levels exhibited a marked increase in the serum of AFB1-intoxicated animals while treatment with CEE reduced the levels of these cytokines implying that the CEE has an antiinflammatory activity against AFB1 toxicity. Previous studies revealed that $C$. majus reduces certain cytokines' synthesis and modulates the values of immune cells and immunoglobulins in mice (Lee et al., 2007), and it was reported that the crude extract and its purified compounds derived from $C$. majus have antiinflammatory properties in in vivo and in vitro studies (Biswas et al., 2002). A similar elevation in TNF- $\alpha$ and IL-1 $\beta$ levels in animals receiving AFB1 has been reported in a previous study (Hamzawy et al., 2013). The increased IL-1 $\beta$ level manifests the presence of inflammation (Safieh-Garabedian et al., 1995). TNF- $\alpha$ has an important role in carcinogenesis (Balkwill, 2009; Moor et al., 1999) and in the induction of hemorrhagic necrosis of the cells challenged with DNA damage (Balkwill, 2009). This suggestion was asserted by the results of DNA fragmentation in our study, where the fragmentation and damage of liver DNA markedly increased in AFB1-intoxicated animals. AFB1 toxicity may increase TNF- $\alpha$ and IL-1 amounts via activation of caspase-3 (an apoptotic marker) (Meik et al., 2001).

Previously, it was stated that the elevation in oxidative stress results in the damage of liver DNA that contributes to apoptosis and necrosis of the hepatic cells (Mukhopadhyay et al., 2011). This damage is achieved as a distinctive event in cell apoptosis (Mourad et al., 2017). Administration of the CEE to the AFB1-treated animals showed a significant decrease in hepatic DNA degeneration as compared to the AFB1-intoxicated group. The reduction of DNA deterioration by CEE treatment may be due to the antioxidant capacity of this extract.

As expected, AFB1 administration produced a state of oxidative stress. This appeared from the significant elevation in nitric oxide and MDA and the significant reduction in the values of glutathione and the antioxidant enzymes (GPx, SOD, and CAT) in the AFB1 group compared to the control group. The antioxidant enzymes which include GPx, SOD, and CAT play an important role in the conversion of oxidative products into harmless molecules (Nimse and Pal, 2015). Our results agreed with the results of ElKady et al. (2010) and Kanbur et al. (2011) who reported that the oxidative stress may be due to the direct action of AFB or by its reactive 8,9-epoxide metabolites and the free radicals generated during the formation of these metabolites. AFB1 increases free radicals' production and elevates lipid peroxidation and hence leads to DNA, lipid, and protein damage and loss of biological functions such as membrane permeability and calcium influx and consequently affects the stability of DNA that leads to cancer (Klaunig et al., 2011; Smela et al., 2001). 
The histopathological examination showed damaged livers with the dense portal and lobular inflammation associated with fibrosis in the group that ingested AFB1 similar to those observed previously (Hamzawy et al., 2013; Poapolathep et al., 2015). Administration of the CEE in combination with AFB1 reduced these pathological changes confirming the protective effect of the CEE on the hepatic cells from degenerative effects induced by the free radicals generated during AFB1 metabolism.

The hepatoprotective effects of the CEE against aflatoxicosis were demonstrated in the current study by suppressing oxidative stress and inflammation that cause DNA and membrane damage. Since the CEE has antioxidant compounds which can inhibit lipid peroxidation and prevent the exhaustion of the endogenous glutathione and antioxidant enzymes, this in turn prevents DNA damage and also improves liver integrity and function and consequently improves lipid metabolism. Another mechanism that participates in the protection against aflatoxicosis is the inhibition of cytochrome P450 enzymes or enhancing GST-mediated in AFB1 detoxification (Hayes et al., 1998), since Liu et al. (2019) proved that chelidonine which is a major constituent of $C$. majus inhibits cytochrome $\mathrm{P} 450$ enzymes mediating the conversion of AFB1 to the reactive 8,9-epoxide.

Based on the obtained results, the CEE showed strong antioxidant activity demonstrated from testing of $\mathrm{DPPH}^{\circ}$ scavenging activity and further confirmed by the data of reducing power ability. This may be due to the rich and diverse phytochemicals present in the extract. The phytochemical analysis of the CEE revealed the presence of phenolic compounds such as chlorogenic acid, gallic acid, syringic acid, ferulic acid, vanillin, caffeic acid, and coumaric acid. These phenolic compounds are considered strong antioxidants which directly scavenge free radicals and inhibit lipid peroxidation (Lee et al., 2003) thus preventing these free radicals from reaching and assaulting the critical molecules such as lipids, DNA, and proteins. For instance, chlorogenic acid, ferulic acid, and vanillin have DPPH and ABTS $\bullet+$ free radical scavenging ability (Yang et al., 2018). In addition, some of the phenol derivatives, such as ferulic acid, caffeic acid, and coumaric acid, have been found to contain decent antioxidant activities (Andreasen et al., 2001).

Other alkaloid compounds have been identified in the ethanolic dry extracts of C. majus, such as chelidonine, protopine, and coptisine (Hiller et al., 1998). It was reported that nano chelidonine administration after cadmium chloride toxicity in mice markedly diminished lipid peroxidation and restored the levels of triglyceride, cholesterol, glutathione, and antioxidant enzymes (Paul et al., 2013). Besides that, C. majus coptisine has been found to reduce oxidative phosphorylation in rats' liver mitochondria (Kamins'ky̌ et al., 1999).

Our results showed that the CEE, when administered alone, did not significantly affect all studied parameters as compared to normal values. These results demonstrate the safety of this extract on liver tissue. Our findings are consistent with those obtained by Mazzanti et al. (2009 and 2013) who reported that the prolonged ingestion of the C. majus extract by Wistar rats appeared to be safe and they excluded cellular toxicity, cholestasis, inflammation, and other diseases that could influence liver function. Conversely, the $C$. majus alkaloid induced hepatotoxic effects in some human cases (Tarantino et al., 2009; Teschke et al., 2011). It has been hypothesized that these toxic effects are attributed to the simultaneous treatment with $C$. majus and other pharmaceutical products such as hormones (estrogens and thyroid hormones) and anti-inflammatory drugs (Benninger et al., 1999).

\section{CONCLUSION}

The present study has demonstrated that the $C$. majus ethanolic extract exhibits pronounced antioxidative activity making it promising as a hepatoprotective agent against hepatotoxicity induced by aflatoxins. At the same time, it is important to point out that the extract dose applied in the present study is safe at that used dose and duration; therefore, further studies are needed to explore the possible toxicity of extra doses.

\section{ACKNOWLEDGMENTS}

The authors thank the National Research Centre (NRC) for its unlimited allowance and for letting the group use the laboratories and instruments during the development of the study.

\section{AUTHOR CONTRIBUTIONS}

All authors made substantial contributions to conception and design, acquisition of data, or analysis and interpretation of data; took part in drafting the article or revising it critically for important intellectual content; agreed to submit to the current journal; gave final approval of the version to be published; and agree to be accountable for all aspects of the work. All the authors are eligible to be an author as per the international committee of medical journal editors (ICMJE) requirements/guidelines.

\section{CONFLICT OF INTERESTS}

The authors declare they have no conflicts of interest.

\section{FUNDING}

There is no funding to report.

\section{DATA AVAILABILITY}

All data generated and analyzed are included within this research article.

\section{PUBLISHER'S NOTE}

This journal remains neutral with regard to jurisdictional claims in published institutional affiliation.

\section{REFERENCES}

Abdel-Wahhab MA, Abdel-Galil MM, Hassan AM, Hassan NH, Nada SA, Saeed A, El-Sayed MM. Zizyphus spina-christi extract protects against aflatoxin B1-intitiated hepatic carcinogenicity. Afr J Trad CAM 4, 2007; 4(3):248-56.

Abdel-Wahhab MA, Aljawish A, El-Nekeety AA, Abdel-Aiezm SH, Abdel-Kader HAM, Rihn BH, Joubert O. Chitosan nano particles and quercetin modulate gene expression and prevent the genotoxicity of aflatoxin B1 in rat liver. Toxicol Rep, 2015; 2:737-47.

Abdel-Wahhab MA, Hassan NS, El-Kady AA, Khadrawy YA, El-Nekeety AA, Mohamed SR, Sharaf HA, Mannaa FA. Red ginseng extract protects against aflatoxin $\mathrm{B} 1$ and fumonisins-induced hepatic precancerous lesions in rats. Food Chem Toxicol, 2010; 48:733-42. 
Alm-Eldeen AA, Mona MH, Shati AA, El-Mekkawy HI. Synergistic effect of black tea and curcumin in improving the hepatotoxicity induced by aflatoxin B1 in rats. Toxicol Ind Health, 2015; 31(12):1269-80.

Andreasen MF, Kroon PA, Williamson G, Garcia-Conesa MT. Esterase activity able to hydrolyze dietary antioxidant hydroxycinnamates is distributed along the intestine of mammals. J Agric Food Chem, 2001; 49:5679-84.

Paul A, Das J, Das S, Samadder A, Khuda-Bukhsh AR. Poly (lactide-co-glycolide) nano-encapsulation of chelidonine, an active bioingredient of greater celandine (C. majus), enhances its ameliorative potential against cadmium induced oxidative stress and hepatic injury in mice. Environ Toxicol Pharmacol, 2013; 36(3):937-47.

Balkwill F. Tumour necrosis factor and cancer. Nat Rev Cancer, 2009; 9:361-71.

Barnes J, Anderson LA, Phillipson JD. Celandine, greater, in herbal medicines. 3rd edition, Pharmaceutical Press, London, UK; Chicago,IL, 2007.

Benninger J, Schneider HT, Schuppan D, Kirchner T, Hahn EG. Acute hepatitis induced by greater celandine (C. majus). Gastroenterol, 1999; 117:1234-7.

Biswas SJ, Khuda-Bukhsh AH. Effect of a homeopathic drug, Chelidonium, in amelioration of p-DAB induced hepatocarcinogenesis in mice. BMC Complement Altern Med, 2002; 2:4-11.

Bozeman EN, Srivatsan S, Mohammadi H, Daniels D, Shashidharamurthy R, Selvaraj P. Ukrain, a plant derived semi-synthetic compound, exerts antitumor effects against murine and human breast cancer and induce protective antitumor immunity in mice. Exp Oncol, 2012; 34:340-7.

Choy WN. A review of the dose-response induction of DNA adducts by aflatoxin B1 and its implications to quantitative cancer risk assessment. Mutat Res, 1993; 296:181-98.

Diao E, Hou H, Chen B, Shan C, Dong H. Ozonolysis efficiency and safety evaluation of aflatoxin B1 in peanuts. Food Chem Toxicol, 2013; 55:519-25.

Drury RA, Wallington EA. Carleton's histological technique. 5th edition, Oxford University Press, New York, NY, 1980.

Eaton DL, Ramsdell H, Neal G. Biotransformation of aflatoxins. In: Eaton DL, Groopman JD (eds.). The toxicology of aflatoxins: human health, veterinary, and agricultural significance. Academic Press, New York, NY, 1994.

Edrington TS, Kamps-Holtzapple CA, Harvey RB, Kubena LF, Elissalde $\mathrm{MH}$, Rottinghaus, GE. Acute hepatic and renal toxicity in lambs dosed with fumonisin containing culture materials. J Anim Sci, 1995; 73:508-15.

Eftekhari A, Ahmadian E, Panahi-Azar V, Hosseini H, Tabibiazar M, Maleki Dizaj S. Hepatoprotective and free radical scavenging actions of quercetin nanoparticles on aflatoxin B1-induced liver damage: in vitro/in vivo studies. Artif Cells Nanomed Biotechnol, 2018; 46(2):411-20.

El-Bahr S. Effect of curcumin on hepatic antioxidant enzymes activities and gene expressions in rats intoxicated with aflatoxin B1. Phytother Res, 2015; 29:134-40.

El-Kady AA, Sharaf HA, Gad AS, Mannaa F, Hassan NS, Abdel-Wahhab MA. Whey protein concentrate and ginseng extract exhibit antioxidant properties in vitro and reduce hepatotoxicity and oxidative stress of aflatoxin in vivo. New York Sci J, 2010; 3(11):37-51.

Ellis EM. Protection against aflatoxin B1 in rat- a new look at the link between toxicity, carcinogenicity and metabolism. Toxicol Sci, 2009; 109:1-3.

Akinrinmade FJ, Akinrinde AS, Amid A. Changes in serum cytokine levels, hepatic and intestinal morphology in aflatoxin B1-induced injury: modulatory roles of melatonin and flavonoid-rich fractions from Chromolena odorata. Mycotoxin Res, 2016; 32(2):53-60.

Filipiak-SzokA, Kurzawa M, Szłyk E, Twarużek M, Błajet-Kosicka A, Grajewski J. Determination of mycotoxins, alkaloids, phytochemicals, antioxidants and cytotoxicity in Asiatic ginseng (Ashwagandha, Dong quai, Panax ginseng). Chem Zvesti, 2017; 71(6):1073-82.

Gilca M, Gaman L, Panait E, Stoian I, Atanasiu V. C. majus--an integrative review: traditional knowledge versus modern findings. Forsch Komplementmed, 2010; 17:241-8.
Hamzawy MA, El-Denshary ESM, Hassan NS, Mannaa F, Abdel-Wahhab MS. Dietary supplementation of Calendula Officinalis counteracts the oxidative stress and liver damage resulted from aflatoxin. ISRN Nutr, 2013; 2013:1-9.

Hayes JD, Pulford DJ, Ellis EM, McLeod R, James RF, Seidegard J, Mosialou E, Jernstrom B, Neal GE. Regulation of rat glutathione S-transferase A5 by cancer chemopreventive agents: mechanisms of inducible resistance to aflatoxin B1. Chem Biol Interact, 1998; 111-112:51-67.

Hiller KO, Ghorbani M, Schilcher H. Antispasmodic and relaxant activity of chelidonine, protopine, coptisine, and $C$. majus extracts on isolated guinea-pig ileum. Planta Med, 1998; 64:758-60.

Ishikawa AT, Hirooka EY, Silva PLA, Bracarense AFRL, Flaiban KKM, Akagi CY, Kawamura O, da Costa MC, Itano EN. Impact of a single oral acute dose of aflatoxin $\mathrm{B} 1$ on liver function/cytokines and the lymphoproliferative response in C57B1/6 mice. Toxins, 2017; 9:374-283.

Ismail A, Gonçalves BL, de Neeff DV, Ponzilacqua B, Coppa CFSC, Hintzsche H, Sajid M, Cruz AG, Corassin CH, Oliveira CAF. Aflatoxin in foodstuffs: occurrence and recent advances in decontamination. Food Res Int, 2018; 113:74-85.

Jang S, Kim BH, Lee W, An SJ, Choi HG, Jeon BH, Chung H, Rho J, Kim Y, Chai K. Stylopine from C. majus inhibits LPS-induced inflammatory mediators in RAW 264.7 cells. Arch Pharm Res, 2004; 27(9):923-9.

Kamins'kyǐ VO, Kryv'iak NV, Lutsyk MD, Stořka RS. Effect of alkaloids from celandine on calcium accumulation and oxidative phosphorylation in mitochondria depending on their DNA intercalating properties. Ukr Biokhim Zh, 2006; 78(2):73-8.

Kanbur M, Eraslan G, Sarica ZS, Aslan O. The effects of evening primrose oil on lipid peroxidation induced by subacute aflatoxin exposure in mice. Food Chem Toxicol, 2011; 49(9):1960-4.

Khan S. Evaluation of hyperbilirubinemia in acute inflammation of appendix: a prospective study of 45 cases. Kathm Univ Med J, 2006; 4:281-9.

Klaunig JE, Wang $\mathrm{Z}, \mathrm{Pu} \mathrm{X}$, Zhou S. Oxidative stress and oxidative damage in chemical carcinogenesis. Toxicol Appl Pharmacol, 2011; 254:86-99.

Lee YC, Kim SH, Roh SS, Choi HY, Seo YB. Suppressive effects of $C$. majus methanol extract in knee joint, regional lymph nodes, and spleen on collagen-induced arthritis in mice. J Ethnopharmacol, 2007; $112: 40-8$.

Lee SR, Im KJ, Suh SI, Jung JG. Protective effect of green tea polyphenol epigallocatechin gallate and other antioxidants on lipid peroxidation in gerbil brain homogenates. Phytother Res, 2003; 17:206-9.

Liao S, Shi D, Clemons-Chevis CL, Guo S, Su R, Qiang P, Tang Z.. Protective role of selenium on aflatoxin b1-induced hepatic dysfunction and apoptosis of liver in ducklings. Biol Trace Elem Res, 2014; 162(13):296-301.

Lin CC, Hsu YF, Lin TC, Hsu FL, Hsu HY. Antioxidant and hepatoprotective activity of punicalagin and punicalin on carbon tetrachlorideinduced liver damage in rats. J Pharm Pharmacol, 1998; 50:789-94.

Liu Y, Peng Y, Zhang Z, Guo X, Ji M, Zheng J. In vitro and in vivo studies of the metabolic activation of chelidonine. Chem Biol Interact, 2019; 308:155-63.

Marcus AK, Milton JC. Current medical diagnosis and treatment. In: Drawer L (ed.). 21st edition, Middle east edition, Lange Medical Publication, Los Altos, CA, 1982

Mazzanti G, Di Sotto A, Franchitto A, Mammola CL, Mariani P, Mastrangelo S, Menniti-Ippolito F, Vitalone A. C. majus is not hepatotoxic in wistar rats, in a 4 weeks feeding experiment. J Ethnopharmacol, 2009; 126:518-24.

Mazzanti G, Sotto AD, Giacomo SD, Durazzi F, Mariani P, Nicoletti M, Mammola CL, Vitalone A. C. majus L. does not potentiate the hepatic effect of acetaminophen. Exp Toxicol Pathol, 2013; 65(78):1117-20.

McLean M, Dutton MF. Cellular interactions and metabolism of aflatoxin: an update. Pharmacol Ther, 1995; 65:163-92. 
Meki AR, Abdel-Ghaffar SK, El-Gibaly I. Aflatoxin B1 induces apoptosis in rat liver: protective effect of melatonin. Neuro Endocrinol Lett, 2009; 22(6):417-26.

Mitra S, Gole M, Samajdar K, Sur RK, Chakraborty BN. Antihepatotoxic activity of C. majus. Int J Pharmacognosy, 1992; 30:125-8.

Mitra S, Sur RK, Roy A, Mukherjee AS. Effect of C. majus L. on experimental hepatic tissue injury. Phytother Res, 1996; 10:354-6.

Mohajeri M, Behnam B, Cicero AFG, Sahebkar A. Protective effects of curcumin against aflatoxicosis: a comprehensive review. J Cell Physiol, 2018; 233:3552-77.

Monmeesil P, Fungfuang W, Tulayakul P, Pongchairerk U. The effects of astaxanthin on liver histopathology and expression of superoxide dismutase in rat aflatoxicosis. J Vet Med Sci, 2019; 81(8):1162-1172.

Moore RJ, Owens DM, Stamp G, Arnott C, Burke F, East N, Holdsworth H, Turner L, Rollins B, Pasparakis M, Kollias G, Balkwill F. Mice deficient in tumor necrosis factor-alpha are resistant to skin carcinogenesis. Nat Med, 1999; 5:828-31.

Mourad HH, EL-Kassaby M, El-Hussieny EA, Esmail RS, Mannaa FA, Abdel-Wahhab KG. Role of soy protein concentrate on oxidative stress and DNA fragmentation in streptozotocin-induced diabetic rats. J Innov Pharma Biol Sci, 2017; 4:16-25.

Mukhopadhyay P, Rajesh M, Horvath B, Batkai S, Park O, Tanchian G, Gao RY, Patel V, Wink DA, Liaudet L, Haskó G, Mechoulam $\mathrm{R}$, Pacher P. Cannabidiol protects against hepatic ischemia/reperfusion injury by attenuating inflammatory signaling and response, oxidative/ nitrative stress, and cell death. Free Radic Biol Med, 2011; 50:1368-81.

Murphy PA, Hendrich S, Landgren C, Bryant CM. Food mycotoxins: an update. J Food Sci, 2006; 71:R51-65.

Nawrot R, Zauber H, Schulze WX. Global proteomic analysis of C. majus and Corydalis cava (Papaveraceae) extracts revealed similar defense-related protein compositions. Fitoterapia, 2014; 94:77-87.

Nimse SB, Pal, D. Free radicals, natural antioxidants, and their reaction mechanisms. RSC Adv, 2015; 5:27986-8006.

Nogala-Kalucka M, Korczak J, Dratwia M, Lampart-Szczapa E, Siger A, Buchowski M. Changes in antioxidant activity and free radical scavenging potential of rosemary extract and tocopherols in isolated rapeseed oil triacylglycerols during accelerated tests. Food Chem, 2005; 93:227-35.

Perandones CE, Illera VA, Peckham D, Stunz LL, Ashman RF. Regulation of apoptosis in vitro in mature murine spleen T cells. J Immunol, 1993; 151(7):3521-9.

Poapolathep S, Imsilp K, Machii K, Kumagai S, Poapolathep A. The effects of curcumin on aflatoxin B1- induced toxicity in rats. Biocontrol Sci, 2015; 20(3):171-7.

Rawal S, Kim JE, Coulombe R. Aflatoxin B1 in poultry: toxicology, metabolism and prevention. Res Vet Sci, 2010; 89:325-31.

Recknagel RO, Glende Jr EA, Briton RS. Free radical damage and lipid peroxidation. In: Hepatotoxicology, Meeks RG (ed.). CRC Press, Boca Raton, FL, pp 401-36, 1991.

Safieh-Garabedian B, Poole S, Allchorne A, Winter J, Woolf CJ. Contribution of interleukin 1 beta to the inflammation-induced increase in nerve growth factor levels and inflammatory hyperalgesia. Bri J Pharmacol, 1995; 115:1265-75.

Schermer S. The blood morphology of laboratory animals. 3rd edition, F.A. Davi, Co, Philadelphia, PL, 42 p, 1967.
Sergent T, Ribonnet L, Kolosova A,Garsou S, Schant A, De Saege S, Van Peteghem C, Larondelle Y, Pussemier L, Schneider YJ Molecular and cellular effects of food contaminants and secondary plant components and their plausible interactions at the intestinal level. Food Chem Toxicol, 2008; 46:813-41.

Sethiya NK, Trivedi A, Mishra S. The total antioxidant content and radical scavenging investigation on 17 phytochemical from dietary plant sources used globally as functional food. Biomed Prev Nutr, 2014; 4: 439-44.

Smela ME, Currier SS, Bailey EA, Essigmann JM. The chemistry and biology of aflatoxin B1: from mutational spectrometry to carcinogenesis. Carcinogenesis, 2001; 22:535-45.

Tarantino G, Pezzullo MG, Di Minno MN, Milone F, Pezzullo LS, Milone M, Capone D. Drug-induced liver injury due to "natural products" used for weight loss: a case report. World J Gastroenterol, 2009; 15: 2414-7.

Teschke R, Glass X, Schulze J. Herbal hepatotoxicity by greater Celandine (C. majus): causality assessment of 22 spontaneous reports. Regul Toxicol Pharmacol, 2011; 61:282-91.

Vahlensieck U, Hahn R, Winterhoff H, Gumbinger HG, Nahrsted A, Kemper FH. The effect of $C$. majus herb extract on choleresis in the isolated perfused rat liver. Planta Medica, 1995; 61:267-70.

Wang L, Potter JJ, Rennie-Tankersley L, Novitskiy G, Sipes J and Mezey E. Effects of retinoic acid on the development of liver fibrosis produced by carbon tetrachloride in mice. Biochem Biophys Acta Mol Basis Dis, 2007; 1772:66-71.

Yang XJ, Dang B, Fan MT. Free and bound phenolic compound content and antioxidant activity of different cultivated blue highland barley varieties from the Qinghai-Tibet Plateau. Molecules, 2018; 23:879; doi:10.3390/molecules23040879

Yang CF, Liu J, Wasser S, Shen HM, Tan CE, Ong CN. Inhibition of ebselen on aflatoxin B1-induced hepatocarcinogenesis in Fisher 344 rats. Carcinogenesis, 2000; 21:2237-43.

Zarei A, Changizi-Ashtiyani S, Rezaei A, Sheidaee H, Nabiyon F. The Effect of C. majus extract on the lipid profile and activity of pituitarygonadal axis in hypercholesterolemic rats. Zahedan J Res Med Sci, 2014; 16(10):18-22.

Zhang LY, Zhan DL, Chen YY, Wang WH, He CY, Lin Y, Lin YC, Lin ZN. Aflatoxin B1 enhances pyroptosis of hepatocytes and activation of Kupffer cells to promote liver inflammatory injury via dephosphorylation of cyclooxygenase-2: an in vitro, ex vivo and in vivo study. Arch. Toxicol,2019; 93(11):3305-20.

How to cite this article:

Gomaa HF, Fadl NN, Elmashad WMA, Abouelfadl DM, Mannaa FA, Abdel-Wahhab KG. Protective efficiency of Chelidonium majus extract against hepatoimmune and DNA changes induced by aflatoxin B1. J Appl Pharm Sci, 2022; 12(03):140-149. 